American Journal of Applied Sciences 6 (5): 820-823, 2009

ISSN 1546-9239

(C) 2009 Science Publications

\title{
Simple and Rapid Method of Isolating Humic Acids from Tropical Peat Soils (Saprists)
}

\author{
${ }^{1}$ Shamsuddin Rosliza, ${ }^{1}$ Osumanu Haruna Ahmed, ${ }^{1}$ Kasim Susilawati, \\ ${ }^{1}$ Nik Muhamad Ab. Majid and ${ }^{2}$ Mohamadu Boyie Jalloh \\ Department of Crop Science, Faculty of Agriculture and Food Science, \\ University Putra Malaysia Bintulu Campus, Sarawak, 97008 Bintulu, Sarawak, Malaysia \\ ${ }^{2}$ School of Sustainable Agriculture, University Malaysia Sabah, Locked
} Bag 2073, 88999 Kota Kinabalu, Sabah, Malaysia

\begin{abstract}
Problem Statement: The isolation (extraction, fractionation and purification) of humic acids (HA) from soils is laborious, time consuming and expensive. The extraction, fractionation and purification periods of these substances vary from $12 \mathrm{~h}-7$ days. In order to facilitate production of HA at competitive cost, this study was conducted to investigate whether a simple and rapid procedure could be developed for isolation of HA from well decomposed tropical peat soils (Saprists). Approach: A $0.1 \mathrm{M} \mathrm{KOH}$ was used to isolate HA of air dry peat soil at 2, 4, 6, 8, 10, 12, 14, 16, 18, 20,22 , and $24 \mathrm{~h}$ extraction periods after which samples (liquid obtained after centrifugation at 16,211 $\mathrm{G}$ for $15 \mathrm{~min}$ ) were fractionated (using $6 \mathrm{M} \mathrm{HCl}$ ) at 2, 4, 6, 8, 10, 12, 14, 16, 18, 20, 22, and $24 \mathrm{~h}$. Samples were purified by washing them five times using distilled water instead of using $\mathrm{HCl}, \mathrm{HF}$, and an expensive process called dialysis that requires 1 to 7 days to purify HA. Each washing time was 10 min. Standard procedures were used to ascertain the purity (Ash, $C, \mathrm{E}_{4} / \mathrm{E}_{6}$, carboxylic, phenolic, total acidity, and $\mathrm{K}, \mathrm{Ca}, \mathrm{Mg}$, and $\mathrm{Na}$ ) and quantity of HA yield. Statistical Analysis System (SAS) was used for statistical analysis. Results: Although there was a linear relationship between extraction period and HA yield, there was no relationship between fractionation period and yield of HA. Distilled water used in this study was effective in purifying HA of the Saprists within $1 \mathrm{~h}$ without altering the true chemical nature of $\mathrm{HA}$ as it significantly reduced the mineral content of $\mathrm{HA}$. Besides, $\mathrm{C}, \mathrm{E}_{4} / \mathrm{E}_{6}$, carboxylic, phenolic, and total acidity of the isolated HA were typical of standard ones. Conclusion: The isolation of HA from peat soils can be reduced to $9 \mathrm{~h}(4 \mathrm{~h}$ extraction period, $4 \mathrm{~h}$ fractionation period and $1 \mathrm{~h}$ purification period) instead of the existing range of 1-7 days.
\end{abstract}

Key words: Humic acids isolation, tropical peat soils, humic substances, saprists

\section{INTRODUCTION}

About 2.5 million ha of peatland can be found in Malaysia. Pineapples and oil palms are among the major crops grown on peat soils. However, the inherent nature of peat soils has been militating against sustainable cultivation of most crops on them as desired. For instance, mature oil palms tend to lean and in some cases fall off. In addition, lack of good anchorage leads to oil palm yield reduction on these soils. In the case of pineapple cultivation on peat soils, the yield decreases with time not withstanding high application of fertilizers even though the practice is not economically viable and environmentally unfriendly ${ }^{[1,2]}$. Besides these impediments, frequent burning of peat soils with the accompanied undesirable economic losses cannot be overemphasized.
Being organic in nature, peat soils are rich in humic substances such as humic acids (HA). At the moment, Malaysia imports HA based fertilizers (mostly foliar). One of the reasons for the importation of HA is that the isolation of these acids from soils is laborious, time consuming and expensive. For example, the extraction, fractionation and purification periods of these substances vary from $12 \mathrm{~h}-7$ days $^{[3-5]}$. Extraction period ranges between 12 and $48 \mathrm{~h}$ even though $24 \mathrm{~h}$ is the usual practice ${ }^{[6-8]}$. Fractionation period ranges between 12 and $24 \mathrm{~h}^{[4,6]}$, although most studies usually use $24 \mathrm{~h}^{[6-8]}$. It must be emphasized that where the state of the art technologies are not available or expensive to afford, particularly in developing countries, it usually takes between 2 to 7 days to purify (removal of mineral matter like ash) HA

Corresponding Author: Osumanu Haruna Ahmed, Department of Crop Science, Faculty of Agriculture and Food Sciences, University Putra Malaysia Bintulu Campus, Sarawak, Malaysia Tel: +6086855406 Fax: +608685415 
Our recent studies have shown that the purification period of HA from composted pineapple leaves could be reduced from 7 days to between 1 and $2 h^{[9,10]}$ but an information such as this is lacking for HA of well decomposed peat soils (Saprists). In another study, we managed to reduce extraction and fractionation periods of $\mathrm{HA}$ in compost from 48 to $17 \mathrm{~h}$ and 24 to $3 \mathrm{~h}$, respectively ${ }^{[9]}$. These relationships are important because they enable the calculation of the maximum and optimum yields of HA with extraction or fractionation or both procedures, an information lacking for HA of Saprists. This study was carried out to investigate whether a simple and rapid procedure could be developed for isolation of HA from Saprists to facilitate the idea of producing organic fertilizers such as ammonium and potassium humates from these soils.

\section{MATERIALS AND METHODS}

The peat soil used in this study was a well decomposed peat from Craun Research, Mukah, Sarawak, Malaysia. The HA extraction was conducted using the procedures described by other authors ${ }^{[9,10,11]}$ with some modifications. Five gram (dry weight basis) peat soil samples at natural moisture content were placed into polyethylene centrifuge bottles $(250 \mathrm{~mL})$ and $50 \mathrm{~mL} 0.1 \mathrm{M} \mathrm{NaOH}$ solution was added and the bottles stoppered tightly with rubber stoppers. The samples were equilibrated at room temperature $\left(25^{\circ} \mathrm{C}\right)$ on a reciprocal mechanical shaker.

The extraction periods used were 4 (EP4), 8 (EP8), 12 (EP12), 16 (EP16), 20 (EP20) and 24 (EP24) h. At the end of each extraction period, the samples were centrifuged at 16,211 G for 15 min (SiGMA, Model 6K 15, Osterode am Harz, Germany). The dark-coloured supernatant liquors were decanted, the $\mathrm{pH}$ of the solutions adjusted to 1.0 with $6 \mathrm{M} \mathrm{HCl}$ and the $\mathrm{HA}$ allowed to stand at room temperature. The fractionation periods used immediately after acidification were 4 (FP4), 8 (FP8), 12 (FP12), 16 (FP16), 20 (FP20) and 24 (FP24), 21 (FP21) h. At the end of each fractionation period, the excess supernatant liquors (fulvic acid) were siphoned off from the acidified extracts. The remainder of the suspensions containing the HA were transferred to polyethylene bottles and centrifuged at $16,211 \mathrm{G}$ for $10 \mathrm{~min}$. The HA samples were purified by washing them in $50 \mathrm{~mL}$ of distilled water through centrifugation at $16,211 \mathrm{G}$ for $10 \mathrm{~min}$ to reduce mineral matter (e.g., $\mathrm{Na}^{+}$) and $\mathrm{HCl}$ (used during acidification). This procedure was repeated 5 times after which the washed HA samples were oven dried at $40{ }^{\circ} \mathrm{C}$ to a constant weight, weighed and yields expressed as percentage by weight of HA in the peat soil used. Carbon and ash contents in HA were determined by combusting the HA at $750^{\circ} \mathrm{C}^{[12]}$ while the carboxylic, phenolic functional groups and total acidity were determined by the method described by ${ }^{[8]} . \mathrm{E}_{4} / \mathrm{E}_{6}$ of the HA was determined by spectroscopy.

It must be noted that that the complete process (extraction, fractionation and fractionation) for this study was replicated 3 times, hence values used in this work were the means of these replications. The relationship between extraction period, fractionation period and the yield of HA, as well the relationship between both variables (extraction period and fractionation period) on the yields of HA were evaluated using the statistical analysis system (SAS) version 9.1.

\section{RESULTS}

The $\mathrm{pH}$ in water and $1 \mathrm{M} \mathrm{KCl}$ of the peat soil were 3.77 and 2.45 , respectively. These values were low but they were typical of tropical peat soils. The organic matter and total carbon contents of the soil were 97 and $56.21 \%$, respectively. These values were also typical of Saprists of Sarawak, Malaysia.

There was a linear relationship between extraction period and yield of HA, (Fig. 1) from the tropical peat soil studied. Contrary to period of extraction, no significant relationship was found between the period of fractionation with yield of HA (Fig. 2). There was no significant interaction between extraction period and fractionation period (Fig. 3).

When HA are extracted they are normally not free from mineral matter. As a result, the purity of HA is usually ascertained from ash content (mineral matter), elemental composition, functional groups, spectral characteristics and so forth. The ash content should not be more than $1 \%$. The ash content of the HA was found to range from $0.3-0.83 \%$, a range less than the generally accepted one.

As shown in Table 1, the contents of $\mathrm{Na}, \mathrm{K}, \mathrm{Ca}$ and $\mathrm{Mg}$ at first washing were generally high but their contents consistently decreased considerably at the fifth washing (Table 1).

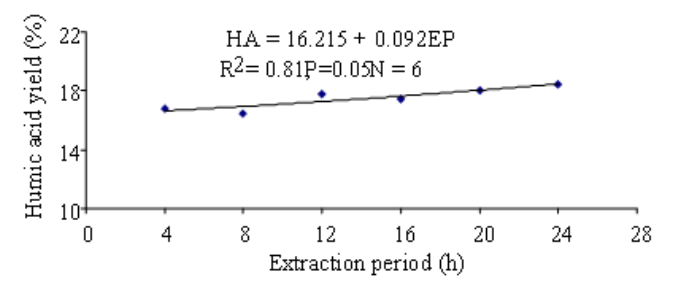

Fig. 1: Relationship between extraction period and humic acids yield 


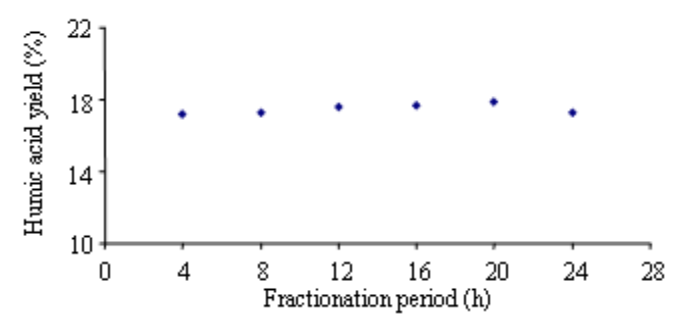

Fig. 2: Relationship between fractionation period and humic acids yield

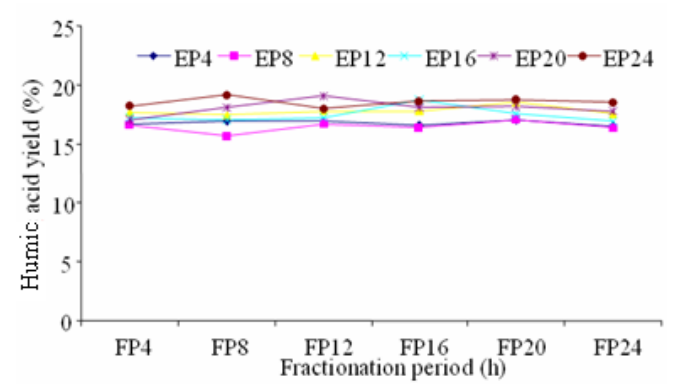

Fig. 3: Performances of fractionation periods under different Extraction Periods (EP). Note, no significant relationship $\mathrm{p}=0.05$ between different fractionation periods and yield of humic acid for different extraction periods studied

Table 1: Ranges of the elemental concentrations in the supernatant solutions at first and fifth washing of peat soil Humic Acids (HA) during purification

\begin{tabular}{lllll}
\hline Purification stage & $\mathrm{Na}$ & $\mathrm{K}\left(\mathrm{mg} \mathrm{L}^{-1}\right)$ & $\mathrm{Ca}$ & $\mathrm{Mg}$ \\
\hline First purification & $91.8-143$ & $0.4-1$ & $6.7-10.8$ & $1-1.4$ \\
Fifth purification & $22.8-66$ & $0.01-0.4$ & $1.9-3.2$ & $0.2-0.5$ \\
\hline
\end{tabular}

Table 2: Comparison of ranges of carbon, phenolic $\mathrm{OH}$, carboxylic $\mathrm{COOH}$, total acidity and E4/E6 of Saprists peat Humic Acids (HA) with related reports

\begin{tabular}{llll}
\hline Variable & Present study & Reference & \\
\hline $\begin{array}{l}\text { Carbon (\%) } \\
\text { Phenolic OH } \\
(\mathrm{cmol} \mathrm{kg}\end{array}$ & $57.05-57.90$ & $48.90-58.50$ & $54.00-59.00$ \\
$\begin{array}{l}\text { Carboxylic COOH } \\
(\mathrm{cmol} \mathrm{kg})\end{array}$ & $433-533$ & $150-440$ & \\
$\begin{array}{l}\text { Total acidity } \\
(\mathrm{cmol} \mathrm{kg})\end{array}$ & $667-950$ & $240-540$ \\
E4/E6 & $6.46-7.24$ & $7-8$ or higher \\
\hline
\end{tabular}

Schnitzer $^{[6]}, \operatorname{Tan}^{[5]}$

The $\mathrm{C}$ content, phenolic $\mathrm{OH}$, carboxylic $\mathrm{COOH}$ and total acidity ranges of the HA in this study were found to be within the ranges reported by other authors (Table 2). Additionally, the $\mathrm{E}_{4} / \mathrm{E}_{6}$ values of the HA which indicate level of humification were comparable with those reported else where

\section{DISCUSSION}

The linear relationship between extraction period and yield of HA was consistent with the observations of Goh and $\operatorname{Reid}^{[3]}$ that the yield of HA increases with increasing extraction period. This finding for Saprists can be explained based on the fact that besides slowing down depolymerisation of high molecular weight complexes, the solubilisation of the peat soil increased with increasing period because the exchange process of $\mathrm{Na}$ ions at the exchange sites (carboxylic, phenolic functional groups) of peat progressed with the extraction period until $24 \mathrm{~h}$, a period when most of these sites may have been saturated with $\mathrm{Na}$ ion, making the peat soil highly soluble and hence the maximum yield at this extraction period. Another reason could be the difficulty of extracting the humic substances in the initial shorter period (e.g., $4 \mathrm{~h}$ ) because of the difficulty of wetting the peat soil due to irreversible drying associated with peat soils upon drying. It must, however, be pointed out that where the characterization of the HA is of primary importance instead of the amount of HA isolated, an optimum yield $(16.54 \%)$ of HA equivalent to optimum extraction period of $4 \mathrm{~h}$ or less could be considered, as the longer the extraction period, the greater will be the chemical changes. Optimum yield was calculated as $90 \%$ of the maximum yield of HA corresponding to maximum extraction period of $24 \mathrm{~h}$ beyond which this yield will not be time wise economical ${ }^{[9,10]}$.

No significant relationship between the period of fractionation with yield of HA suggests that the yield of HA was not affected by fractionation period. Therefore, it is assumed that the minimum fractionation period in this study is $4 \mathrm{~h}$. This is because the fractionation period was sufficient for the $\mathrm{H}$ ions (after acidification with $6 \mathrm{M} \mathrm{HCl}$ ) to displace $\mathrm{Na}$ ions and other cations at the exchange complexes of the HA.

Furthermore, the fact that there was no significant interaction between extraction period and fractionation period (Fig. 3) suggests that the performances of the different fractionation periods with any of the extraction periods is the same, therefore it is reasonable to assume that $4 \mathrm{~h}$ of equilibration after acidification is sufficient to displace the sodium ions with hydrogen ions at the exchange sites of the HA.

The low ash content suggests that the HA in this study contained a relatively low content of inorganic ions. The relatively low ash content of the HA indicates that the purification process was effective in reducing mineral matter.

Apart from removing cations in solution, the excess water used during purification served as 
Bronsted-Lowry acid thereby donating more hydrogen ions which effectively replaced some of the remaining $\mathrm{Na}, \mathrm{K}, \mathrm{Ca}$ and $\mathrm{Mg}$ at the exchange complexes of the HA which were not replaced by hydrogen ions (during acidification with $6 \mathrm{M} \mathrm{HCl}$ ) during fractionation (precipitation). The consistency of the range of carbon content of the HA (Table 2) with those reported by ${ }^{[13,15]}$ also confirms the purity of the HA, a further indication of the purity of the HA.

The relatively high $\mathrm{E}_{4} / \mathrm{E}_{6}$ values indicate prominence of aliphatic components or the HA in this study are of relatively low molecular weights ${ }^{[6,13]}$.

\section{CONCLUSION}

The nature of the relationship between period of extraction and yield of HA from Saprists peat is linear. The optimum yield of HA can be obtained at extraction period of $4 \mathrm{~h}$. There is no relationship between period of fractionation and yield of HA, so from an economic point of view $4 \mathrm{~h}$ is sufficient to equilibrate HA immediately after acidification for tropical peat soils. The HA can be purified within $1 \mathrm{~h}$ using distilled water. The significance of this study is that HA of tropical peat soils can be isolated within $9 \mathrm{~h}$ (i.e., $4 \mathrm{~h}$ extraction period, $4 \mathrm{~h}$ fractionation period and $1 \mathrm{~h}$ purification period) or less instead of the existing range of 1 to 7 days, hence helping in facilitating the idea of producing ammonium and potassium humates from tropical peat soils, a practice that could have less undesirable environmental effects.

\section{ACKNOWLEDGMENT}

The authors acknowledge the financial support of this research by the Ministry of Higher Education Malaysia.

\section{REFERENCES}

1. Ahmed, O.H., M.H.A. Husni, M.M . Hanafi, A.R. Anuar and S.R. Syed Omar, 2006. Leaching losses of soil applied potassium fertilizer in pineapple cultivation on tropical peat soils in Malaysia. N.Z. J. Crop Hortic. Sci., 34: 155-162. http://www.royalsociety.org.nz/Site/publish/Journa 1s/nzjchs/2006/022.aspx

2. Ahmed, O.H., M.H.A. Husni, M.M. Hanafi, A.R. Anuar and S.R. Syed Omar, 2007 Phosphorus fertilizer use in pineapple cultivation with in situ residues burning on organic soils. Comm. Soil Sci. Plant Anal, 38: 1243-1254. DOI: $10.1080 / 00103620701328388$
3. Goh, K.M. and M.R.Reid, 1975. Molecular weight distribution of soil organic matter as affected by acid pre-treated and fractionation into humic and fulvic acids. J. Soil Sci., 26: 207-217. DOI: 10.1111/j.1365-2389.1975.tb01944.x

4. Kakezawa, M., T. Nishida and Y. Takahara, 1992. Structural characteristics of humic acids extracted from woody composts by two-step composting process. Soil Sci. Plant Nutr., 38: 85-92. http://wwwsoc.nii.ac.jp/jssspn/kaishi/fsspn38.html $\# 1$

5. Tan, K.H., 2003. Humic Matter in Soil and the Environment: Principles and Controversies. Marcel Dekker, Inc., New York, pp:34-71. DOI:10.1016/j.agsy.2005.03.010

6. Schnitzer, M. and C.M. Preston, 1986. Analysis of humic acids by solution and solid-state carbon-13 nuclear magnetic resonance. Soil Sci. Soc. Am. J., 50: 326-331. http://soil.scijournals.org/

7. De Nobili, M. G.J. Bragato, M. Alcaniz, A. Puigbo and L. Comelllas, 1990. Characterization of electrophoretic fractions of humic substances with different electrofocusing behaviour. Soil Sci., 150: 763-770. Online ISSN: 1538-9243

8. Inbar, Y., Y. Chen and Y. Hadar, 1990. Humic substances formed during the composting of organic matter. Soil Sci. Am. J., 54: 1316-1323. http://soil.scijournals.org/

9. Ahmed, O.H., M.H.A. Husni, A.R. Anuar and M.M. Hanafi, 2005. Determination of minimal duration necessary for the isolation of humic acid contained in composted pineapple leaves. Fruits 60: 115-120. DOI: 10.1051 /fruits:2005022

10. Susilawati, K. O.H. Ahmed, A.M. Nik Muhamad and M.Y. Khanif, 2007. Effects of extraction and fractionation period on the yield of a tropical peat soil (Hemists) humic acids. ISSN: 1557-4997 (Online), Am. J. Agri. Biol. Sci., 2: 202-205.

11 Amalfitano, C., R.A. Quezada, M.A. Wilson and J.V. Hanna, 1995. Chemical composition of humic acids: A comparison with precursor light fraction litter from different vegetations using spectroscopic techniques. Soil Sci., 150: 391-401. Online ISSN: 1538-9243

12. Cheftez, B., P.G. Hatcher, Y. Hadar and Y. Chen, 1996. Chemical and biological characterization of organic matter during composting of municipal solid waste. J. Environ. Qual., 25: 776-785. http://jeq.scijournals.org/cgi/reprint/25/4/776

13. Fong, S.S. and M. Mohamed, 2007. Chemical characterization of humic substances occurring in the peats of Sarawak, Malaysia. Organic Geoc, 38, 967-976. DOI:10.1016/j.orggeochem.2006.12.010 